\title{
Developing a Model for Promoting Professional Ethics of Faculty Members at the Islamic Azad University in the Dimension of Education
}

\author{
Leila Mir Taheri $^{1}$ \& Hamid Maleki ${ }^{2}$ \\ ${ }^{1}$ Phd in Higher Education Management, Department of Management, Tehran Science and research Branch, \\ Islamic Azad University, Tehran, Iran \\ ${ }^{2}$ Assisstant professor, Department of Education Management, Payame Noor University, PO BOX 19395-3697, \\ Tehran, Iran \\ Correspondence: Leila MirTaheri, Phd in Higher Education Management, Department of Management, Tehran \\ Science and research Branch, Islamic Azad University, Tehran, Iran. E-mail: 24mirtaheri@gmail.com
}

Received: July 6, 2016

Accepted: August 7, 2016

Online Published: September 12, 2016

doi:10.5539/mas.v10n10p252

URL: http://dx.doi.org/10.5539/mas.v10n10p252

\begin{abstract}
The current research aimed to develop a model for promoting professional ethics of faculty members of the Islamic Azad University. For this, the most important components and areas of professional ethics were identified; also, relationship between professional ethics and some demographic characteristics, including gender, age and educational major were addressed. To meet this goal, a sample of education practitioners, faculty members and doctoral students was selected via a purposive sampling method for the qualitative part of the research. Also, via studying documents and interviews conducted with the academic practitioners and doctoral students, professional ethics related components were identified, and accordingly, an inventory consisting of 81 items was prepared and was administered to 600 faculty members of Azad University. Factorial analysis results indicated that the individual area consisted of 4 components, which explained $78 / 53 \%$ of its variance in total; organizational area consisted of 3 components which explained $68 / 96 \%$ of its variance and one factor was obtained within the environmental area that explained $86 / 82 \%$ of its variance. Results of structural equations modeling suggested that the recommended conceptual model enjoyed some acceptable goodness of fit with data. Findings pertaining to the validation of the model, including five parts (philosophy and objectives, theoretical basics, perception framework, administrative stages and evaluation system) illustrated that the model enjoys good validity from the views of experts.
\end{abstract}

Keywords: model, professional ethics, faculty member, factorial analysis

\section{Introduction}

One of the main issues which is now raised in then professional system is the discussion of ethics and ethical components. Today, ethics is known as one of the most important variables in the success of organizations and as professional ethics prevails, the organizations will be able to reduce tensions and attain success in regard to accomplish objectives to a great extent; hence, having professional ethics in organizations is considered to be a competitive privilege (Salehi, 2010). Although people do not share a unified approach with regards to success and its definition, they are the same in seeking success. The common and meaningful ideal of mankind is success in the private, professional and organizational life. To attain success and appropriate accountability, the organizations faces with numerous appropriate and inappropriate ways. Management is nothing except for understanding ways in which the organization can reach success sand planning for promoting them (Ibid). Since, the human force is considered to be the factor for a competitive privilege, either individually or collectively, and in interaction with others, peoples' judgment regarding correctness and incorrectness of tasks will influence quantity and quality of their functions and consequential successful performance of the organization. Thus, attention to ethical principles for the organizations is known to be an indispensable necessity (Borghani Farahani, 2011).

Observance of ethics in the organization's treatment of all kinds of internal and external stakeholders results in legitimacy of the organization's measures and use of privileges resulting from increased multiplicity and finally 
in creation of strong competitive privilege and improvement of profitability (Ibid). For the same reason, one of the most important concerns for the modern managers is to create an appropriate framework for thee human forces working in all professions with the aim of increasing sense of responsibility and working commitment in them (Salehi, 2010).

Prevalence of professional ethics will entail many benefits for the organization. Of which we can refer to improving relations, increasing climate of understanding and reducing conflicts, increasing commitment and more responsibility taking on the part of staffs and reducing costs incurred by control (Alizade et al., 2011). In addition, observing professional ethics, from the view of social responsibility will be accompanied by such privileges as increasing legitimacy of the organization as well as its measures, and attention to the stakeholders' expectations, profitability and success for the organization. Thus, as professional ethics overshadows, it will be a key factor or the destiny of the organization (Saki, 2011; Hezjazi \& Mosaferi, 2012).

In this regard, universities and higher institutions, as the most sensitive institutes in the world, and maybe in later centuries, require addressing ethical principles in the area of their own missions and profession. Overall, it can be stated that in recent years, professional ethics in general and education professional ethics in specific have been focused attention among students and faculty members and among scholars and researches within the education management. In many of the universities across the world, regulations with the headings of professional ethics codes have been formulated in which faculty members' area duty bound to observe many of the ethical principles (Faramhini \& Behnam, 2012).

Having said this, the current research, after identification of professional ethics components, aimed to present a conceptual model and examine this model via data obtained from faculty members. It also addressed the components of this construct so as to determine whether or not there is a significant difference among known components from a quantitative or qualitative point of view.

\section{Theoretical Basics and Research Literature}

Ethics has been taken from the Greek word of "Etikos", meaning habit character, mood, destiny, method and the like. Some linguists maintain that the word "ethics" has been adopted from the Latin word "ethocs", whose literal meaning is "character" and it refers to a set of beliefs and perspectives related with the human's traits which guide behaviors of people, groups, entities and nations (Saki, 2011). Velasquez argues that ethics is referred to a process of investigating spiritual and conscience based standards of an individual or of a society (Farastkhah, 2006).Eweje and Brunton (2010) have considered a threefold approach for the applied ethics:

First approach: special attention directed at scientific and controversial instances and at resolving ethical problems; second approach: the application of principles, values and ethical theories as simply motivated by analysis and evaluation of a social performance and policies existing in various professions; third approach: investigation of philosophy of applying ethical theories for understanding one's ethical duties. Applied ethics involves multiple areas: sports, engineering, medical environmental, trading, instruction ethics and etc. Many of these areas are branches of "professional ethics". Some have defined professional ethics as "ethical responsibility" which adrreses ethical duties and responsibilities of the organization against domestic and external perimeter rights (Gharamalaki, 2008:14).

\section{Concept of Professional Ethics}

By professional ethics, it is a set of rules that need to be observed by people voluntarily and based the inward call and their conscience while doing professional tasks; without being externally obliged to do so, or they will be legally punished in case they commit wrongdoing (Gharamalaki, 2010). Professional ethics addresses ethical issues and questions as well as ethical principles of a professional system and refers to ethics in then professional setting (Bestanian, 2011). Generally speaking, the simplest notion in defining professional ethics is to regard it as taking responsibility in the professional life. Professional ethics is classified in two groups with respect to the fact whether or not the person in charge possesses a real or a legal character in this sort of responsibility:

a) Individual ethical responsibility in life: an individual within the society assumes duties which failure to act upon them for attending to them will affect his professional life and thus, his professional ethics will be hurt.

b) Organizational ethical responsibility against domestic and external elements of the environment: the individual in the internal and external setting of the working place assumes some duties which acting upon the will render in the accomplishment of professional ethics (Faramarz Gharamalaki, 2006: 101). 


\section{Professional Ethics in Higher Education}

Efficacy of the academic functioning, as a determining and sensitive organization, depends on a series of individual, professional and organizational factors. In this connection, competencies and proficiency of faculty members and professional qualification as well as their duty to observe as series of professional principles and standards at the university will have a determining role in increasing efficacy of educational activities (Azizi, 2010).

In Higher education, ethics is concerned with delimiting appropriate and inappropriate behaviors and guiding managers and faculty members in administering professional responsibilities (Eweje \& Brunton, 2010). Generally, via considering intra-organizational players and core players of the organization which are constituted by academic officials, faculty members and students as well as educational missions, research and culture and social services done by such members and also by considering the discourses raised in regard to ethical criteria of the premium universities, one can classify ethical criteria in the higher education into four managerial, educational research and student groups (Araste \& Jahed, 2011: 35).

Ethical instructions and guidelines cannot alone form ethical behaviors at universities (Campbell, 2013). However, higher education managers have the role of formulating some ethical criteria at universities and the norms used by them and behaviors arising from such norms will create patterns that indicate what is variable and acceptable (Begernhenegouwen, 2012).

\section{Ethical Principles in Higher Education}

Professional ethics in the area of higher education is based on five main principles. These principles help students and professors to gen engaged in the framework of professional ethics within the areas of education research and scientific crusade. These principles are: 1. Principle of respect for position and freedom of man; 2. Principle of conscientiousness and accountability; 3. Principle of usefulness and non-infliction of harm; 4. Principle of no discrimination and 5. Principle of attention to society's value systems (Evers, 2000).

\section{Professional Ethics of Faculty Members}

The three major groups influencing and being influenced by the educational functioning are: managers and policy makers, faculty members and students. In this regard, faculty members assume the main role in guiding and administering the very task of education.

Obedience of faculty members to principles and values or professional ethics is essential, from the perspective of development of organizational culture based on ethics and from the view of transference of human discriminative traits and characteristics and as a result, their dissemination in the society. Academic professors, disregard of their own specialized discipline who need to have specialty therein, must be skillful in then teaching profession since their assume they assume the duty of teaching ; moreover, they need to be also familiar with professional principles, because education is the primary function and mission of the university (Nemati \& Mohseni, 2010:16). Education provided by an educational system might lead to the incidence of special behaviors in the society which can be criticized and examined from an ethical point of view. For instance, teaching can render in acceptable learning on the part of students in line with scientific developments and society's demands. Educational sources, content and lessons rubrics might be in such a way which strengthen or weaken a special kind of thinking which entails numerous benefits and harms for the society; the professor's kind of behavior can leave positive or negative effects on the students' behaviors and traits (Farastkhah, 2006:10). Therefore, professional ethics principles can be discussed in two dimensions: first, ethical standards that need to be observed on the area of education and pertain to teaching and learning process. Second, individual ethical principles the person needs to oblige himself to observe them anytime anywhere (Nemati \& Mohseni, 2010:16).

Rybold et al (2008) addressed professional ethics and their values. They argued that ethical standards and rules will guide the individual with clear evidence towards correct behavior. Therefore, professional ethics is a criterion for maintaining professional character a $\mathrm{d}$ doing acceptable behavior. Ethical code of conduct is also a statement which describes acceptable professional ethics and ethical behavior of people in resolving ethical crises. In a research with the title of Investigating professors' ethical perceptions, conducted at the University of New Zealand, Eweje and Brunton (2010) concluded that the from the view of academic professors the most important ethics components are: Possessing necessary scientific qualification for teaching, respect for students and realism and justice centeredness in evaluation. In this regard, they assigned the least score to avoiding discrimination among students. Oldenburg (2013) conducted a study with the aim of examining Students' attitudes to professors' ethical; issues. He found out that the most important ethical expectation of students from an ethics centered professor is respect for students and their ideas within various scientific areas and also 
application of proper ways of evaluation which are consistent with that which is taught. In a study with the heading of Examining educational ethical status of faculty members of state universities in the city of Tehran from the perspective of students in the M.A. course, Araste et al. (2010) did a research with a statistical population of all students studying in M.A. courses at the said universities with an inventory. The results which were obtained via using single sample $t$ tests as well as confirmatory factorial analysis suggested that academic professors attached significant value for the issue of ethics and its observance in teaching and paid attention to observing this issue as well as its principles and components in their own teaching processes. It is added that the components under measurement were: effectiveness of lesson's content, addressing sensitive subject matters, attention to the thinking growth of students, avoiding establishing a mutual relationship with students, respect for the university, respect for colleagues, keeping secrets and fair evaluation of students. Ayazi and colleagues (2010) did a research with the goal of Determining ethical characteristics of professors in line with effectiveness of education and found out that merit for teaching, maintaining position and stature of science and knowledge, giving science out for its followers, respect for students, attempts for making students creative with regards to higher traits and ethical values, equality between students, developing thinking among students, respect for rightfulness and fairness, intimacy with students, simplicity of expression, observing equality and spiritual directions are among the most significant traits of professors. In a study with the heading of Investigating and identifying ethical and professional indicators in teaching and education from the viewpoint of M.A. students which was conducted with a qualitative approach and by using a semi-structured interview tool, Motallebi Fard et al (2011) found out that except for the component of "respect for institution" and "keeping secret", other components obtained in the research by Murray et al. hold true at the university of Tarbyat Moalem in Tehran. In addition, their findings introduced component "resect for the classroom" also.

\section{Methodology}

The current research has been done with a mixed methods approach. Study via mixed methods requires gathering and analysis of quantitative and qualitative data in a study in which data are gathered concurrently or sequentially and the mix of data is done in one or several stages of research (Creswell et al., 2003).

\section{Population, Sample and Sampling Method}

In the qualitative part, the statistical population of this study consisted of proficient, elite, managers and experts of higher education and faculty members as well as doctoral students. The number of 6131 people was teaching in the academic year of 2014-2015 as the faculty member at the Islamic Azad University. Sampling in the qualitative part was done and interviews were conducted until reaching the saturation level. This state occurs once when no more data enter into the research that would hence culminate in development, modification, enlargement and addition to the existing theories. The statistical population, in the quantity part, included faculty members of the Azad University who were teaching at the said university in 2014-2015 and the necessary sample in the quantitative part of the research was selected from among them. One of the criteria for determining the sample universe in the quantitative part of the research, especially for using the factorial analysis was estimation of the proportion of the sample volume to the number of variables measured. The recommended ration is about 5-10 (Fabrigar et al. 1999). Sampling in the quantitative part was through classified random method. The researcher was also successful in completing questionnaires on a sample of 600 people from faculty members in district 8 of the said university.

\section{Data Gathering Method}

To gather necessary and main data and information, two library and field methods were used: at the library level, library method was used for reviewing the existing literature. Then, consistent with the research's objectives, interview and questionnaire were applied. The researcher, in the field task, has used an inventory consisting of 81 questions for gathering views of doctorial students in the district 8 of the Islamic Azad University.

\section{Measurement Tool, Administration and its Evaluation}

Gathering of data in the qualitative stage was done by two main strategies: a) examining previous documents and researches in the area of professional ethics in the dimension of education; b) conducting interviews with open-ended answers. At first, to obtain a range of the subject and design the interview's questions, existing texts and research reports in this regard were analyzed with a content analysis approach and in the later stage, the questionnaire's questions having been designed, various dimensions of " professional ethics of faculty members in the dimension of education" within the organization were explored.

In order to obtain content validity and face validity of the measurement tool prior to the administration, the views of relevant experts and researchers as well as those of the key and informed people at the university in regard to 
the credibility of the questionnaire's questions were investigate and meantime, the construct validity, being the most important part of validity investigation in this research was investigated through explanatory and confirmatory factorial analyses.

The administration process of the questionnaires in the quantitative part proceeded as if the researcher became successful at completing the questionnaires on a sample of almost 600 faculty members in the district 8 of t5the Azad University. For this, given theoretical basics and literature review, components and areas related with professional ethics were extracted. Accordingly, Components were formed in three individual, organizational and environmental areas and a total of components which will be explained in the analysis part provide a preliminary insight in the area of professional ethics components. Thereafter, a questionnaire made up of 81 questions were prepared which would examine the professional ethics in two stages of status quo and acceptable state in a six degree scale from too much to very little. The final questionnaire was completed in order to validity the recommended model by experts in the area of higher education and is comprised of five sections: philosophy and objectives, theoretical basics, perceptual framework, model's administrative stages, evaluation system and renewed engineering.

\section{Validity of the Measuring Tool}

\section{Construct validity}

To investigate whether or not the researcher made questionnaire's series of questions enjoy appropriate validity, factorial analysis was applied in the area of construct validity and through this, the questionnaire's factorial analysis was determined. To evaluate the correlation matrix, Keiser- Meyer- Oklin (KMO) for determining the sufficiency of sampling whose acceptable value is greater than $0 / 6$ and the Chi-Two test significant value or Bartel's sphericity were applied. Significance of Chi-two test and Bartel's test are the minimum requirements for a factorial analysis.

Table 1. KMO value and Bartel's test results for the correlation matrix

\begin{tabular}{lllll}
\hline \multirow{2}{*}{ Area } & Sufficiency test of KMO sampling & \multicolumn{3}{l}{ Bartel's sphericity } \\
\cline { 3 - 5 } & & Chi-two value & Freedom degree & Significance \\
\hline Individual & $0 / 646$ & $878 / 76$ & 231 & $0 / 001$ \\
Organizational & $0 / 647$ & $126 / 29$ & 21 & $0 / 001$ \\
Environmental & $0 / 846$ & $1123 / 5$ & 10 & $0 / 001$ \\
\hline
\end{tabular}

As seen from the table above, KMO value for the individual, environmental and organizational arras were $0 / 646$, $0 / 647$ and $0 / 846$ respectively, implying confirmatory factorial analysis. Bartel's statistic is significant for all three areas at the $\mathrm{p}<0 / 01$ level. Thus, there is a necessary correlation among al variables and the minimum necessary conditions for the factorial analysis are met. In other words, factorial analysis results indicate that the measuring tool enjoys acceptable construct validity.

Tool's reliability: The reliability level in the current research was estimated through Cronbach's alpha coefficient. Estimated Cronbach's alpha coefficient for the subscales of individual, organization and environmental areas is $0 / 98,0 / 95$ and $0 / 96$ respectively.

\section{Data Analysis Method}

To analyze data gathered, SPSS 20 and Lisrel 8.7 software were used and to compare scores and score mean, in addition to using descriptive statistics indices, including percentage, frequency, mean, SD and minimum and maximum scores, inferential statistics, including factorial analysis via analysis of main components with a varimax rotation and Youman Whitney and Kruskal Wallis non-parametric tests were applied.

\section{Research Findings}

In this research three main questions were introduced, where a summary of the most important of the research findings in answering the questions is provided; however, the intended sample will be at first addressed. 
Table 2. Frequency of Azad University district 8 faculty members as distinguished by educational major, age and admission year

\begin{tabular}{|c|c|c|c|c|c|c|c|}
\hline & \multicolumn{4}{|l|}{ Major } & \multirow[b]{2}{*}{ Tota } \\
\hline \multicolumn{3}{|c|}{ Admission year } & \multicolumn{4}{|l|}{ Technical-engineering } & \\
\hline \multirow{5}{*}{ 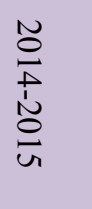 } & \multirow{5}{*}{ Age } & Less than 30 & 14 & 8 & 12 & 2 & 36 \\
\hline & & $31-35$ & 18 & 14 & 18 & 4 & 54 \\
\hline & & $36-40$ & 0 & 8 & 12 & 0 & 20 \\
\hline & & \multirow[t]{2}{*}{ Over 40} & 2 & 4 & 6 & 0 & 12 \\
\hline & & & 34 & 34 & 48 & 6 & 122 \\
\hline \multirow{5}{*}{ 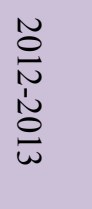 } & & Less than 30 & 20 & 0 & 22 & 0 & 42 \\
\hline & & $31-35$ & 12 & 24 & 26 & 0 & 62 \\
\hline & & $36-40$ & 6 & 12 & 6 & 4 & 28 \\
\hline & Age & Over 40 & 2 & 6 & 6 & 0 & 14 \\
\hline & \multirow[t]{4}{*}{ Total } & & 40 & 42 & 60 & 4 & 146 \\
\hline \multirow{2}{*}{$\stackrel{N}{\varrho}$} & & Less than 30 & 10 & 0 & 18 & 0 & 28 \\
\hline & & $31-35$ & 8 & 16 & 22 & 0 & 46 \\
\hline \multirow{3}{*}{$\frac{\hat{N}}{\stackrel{N}{N}}$} & & $36-40$ & 8 & 14 & 56 & 0 & 78 \\
\hline & Age & Over 40 & 4 & 0 & 2 & 0 & 6 \\
\hline & \multirow[t]{4}{*}{ Total } & & 30 & 30 & 98 & 0 & 158 \\
\hline \multirow{4}{*}{$\begin{array}{l}\text { No } \\
\stackrel{0}{0} \\
\stackrel{1}{0} \\
\stackrel{0}{ }\end{array}$} & & Less than 30 & 12 & 2 & 6 & 2 & 22 \\
\hline & & $31-35$ & 4 & 0 & 40 & 0 & 44 \\
\hline & & $36-40$ & 8 & 4 & 30 & 2 & 44 \\
\hline & Age & Over 40 & 6 & 10 & 38 & 0 & 54 \\
\hline & \multirow[t]{2}{*}{ Total } & & 30 & 16 & 114 & 4 & 164 \\
\hline & & $36-40$ & 0 & 0 & 4 & 0 & 4 \\
\hline & Age & Over 40 & 0 & 0 & 6 & 0 & 6 \\
\hline \multirow[t]{5}{*}{ Other } & \multirow[t]{5}{*}{ Total } & & 0 & 0 & 10 & 0 & 10 \\
\hline & & Less than 30 & 66 & 10 & 58 & 4 & 138 \\
\hline & & $31-35$ & 42 & 64 & 126 & 4 & 236 \\
\hline & & $36-40$ & 22 & 48 & 108 & 6 & 184 \\
\hline & & Over 40 & 14 & 20 & 38 & 0 & 72 \\
\hline Total & \multicolumn{2}{|l|}{ Total } & 124 & 142 & 290 & 36 & 592 \\
\hline
\end{tabular}

The results of the above table classify the frequency of the participants based on major, admission year and age. According to the research results, it is clear that the highest participants relate to the Humanities aged 31-35 and their admission was 2010-2011.

Research fist question: What are the main components and areas for promoting professional ethics of academic faculty members? To account for this question main components of professional ethics were extracted from the investigation of the research literature and the views of the elite and they were included in the 81 question questionnaire for the existing status quo and acceptable state. Then, explanatory factorial analysis was used for the extraction of factors by way of main components and with the varimax rotation and then results of each area was examined separately.

Table 3. Initial statistical indices by using the analysis method of main components of the individual area

\begin{tabular}{lllllll}
\hline Components & \multicolumn{2}{l}{ Initial eigenvalue } & \multicolumn{3}{c}{ Square sum of factorial loads extracted } \\
& Total & Variance percentage & Accumulated percentage & Total & Variance percentage & Accumulated percentage \\
\hline & $24 / 47$ & $54 / 38$ & $54 / 38$ & $24 / 47$ & $54 / 38$ & $54 / 38$ \\
2 & $5 / 89$ & $13 / 08$ & $67 / 46$ & $5 / 89$ & $13 / 08$ & $67 / 46$ \\
3 & $2 / 90$ & $6 / 45$ & $73 / 91$ & $2 / 90$ & $6 / 45$ & $73 / 91$ \\
4 & $2 / 08$ & $4 / 62$ & $78 / 53$ & $2 / 08$ & $4 / 62$ & $78 / 53$ \\
\hline
\end{tabular}


Based on Keiser's criterion, factors having eigenvalue greater than one can be extracted as factors and as seen from the table, four values having eigenvalue are greater than one and these four factors will explain $78 \%$ of the total variance. As seen, $54 / 38 \%$ of the total variance is explained by the first factor, $13 / 08 \%$ by then second factor, $6 / 45 \%$ by the third factors and $4 / 62 \%$ by the fourth factor. Totally, these four factors explain $78 / 53 \%$ of the total variance of the questionnaire. Given explanatory factorial analysis and combination of questions and the factors of this variable, the first factor can be designated as factor "responsibility taking" and hence, the second factors can be named "benefaction", the third factor can be called "candor" while the fourth factor is called "justice".

Table 4. Initial statistical indices by using main components analysis of the organizational area

\begin{tabular}{lllllll}
\hline \multirow{2}{*}{ Components } & \multicolumn{2}{l}{ Initial eigenvalue } & \multicolumn{3}{c}{ Square sum of factorial loads extracted } \\
& Total & Variance percentage & Accumulated percentage & Total & Variance percentage & Accumulated percentage \\
\hline 1 & $13 / 95$ & 45 & 45 & $13 / 95$ & 45 & 45 \\
2 & $4 / 54$ & $14 / 66$ & $59 / 65$ & $4 / 54$ & $14 / 66$ & $59 / 65$ \\
3 & $2 / 88$ & $9 / 30$ & $68 / 96$ & $2 / 88$ & $9 / 30$ & $68 / 96$ \\
\hline
\end{tabular}

As seen from the table, three factors have eigenvalue greater than one and these three factors will totally explain $68 / 96 \%$ of the total variance. The first factor explains $45 / 00 \%$ of the total variance, the second factor explains $14 / 66 \%$ and the third factor explains $9 / 30 \%$ of the total variance. Given explanatory factorial analysis for the organizational area scale, the first factor can be designated as "organizational leadership and management", the second factor "organizational culture" and for this, the third factor is "organizational structure".

Table 5. Initial statistical indices by using main components analysis of the environmental area

\begin{tabular}{lllllll}
\hline \multirow{2}{*}{ Components } & \multicolumn{2}{l}{ Initial eigenvalue } & & \multicolumn{2}{c}{ Square sum of factorial loads extracted } \\
\cline { 2 - 7 } & Total & Variance percentage & Accumulated percentage & Total & Variance percentage & Accumulated percentage \\
\hline 1 & $4 / 34$ & $86 / 82$ & $86 / 82$ & $4 / 34$ & $86 / 82$ & $86 / 82$ \\
\hline
\end{tabular}

As seen from the table, only one factor has eigenvalue greater than one and this factor explains $86 / 82 \%$ of the total variance.

Second question: Is there any significant difference between components identified for the promotion of professional ethics in terms of gender, age, educational major and year of admission? To account for the gender related differences in the components identified for the promotion of professors' professional ethics, given the non-normalcy of the distribution of dependent variables, Youman Whitney non-parametric tests were applied where the results are provided in the following table.

Table 6. Youman Whitney test for examining professional ethics differences in gender groups

\begin{tabular}{lllll}
\hline Group variable & Dependent variable & Youman Whitney statistic & $\mathrm{Z}$ & Sig. \\
\hline Gender & Responsibility taking & 7990 & $0 / 875$ & $0 / 381$ \\
& Justice & $7712 / 5$ & $-1 / 334$ & $0 / 182$ \\
& Candor & $7967 / 5$ & $-0 / 915$ & $0 / 360$ \\
& Benefaction & 8225 & $-0 / 492$ & $0 / 623$ \\
& Organizational culture & 7841 & $-1 / 121$ & $0 / 262$ \\
& Organizational structure & 8401 & $-0 / 205$ & $0 / 838$ \\
& Management and organizational leadership & $8419 / 5$ & $-0 / 174$ & $0 / 862$ \\
& Environmental factor & $8254 / 5$ & $-0 / 444$ & $0 / 657$ \\
\hline
\end{tabular}

Youman Whitney test results indicate that in the variable of gender, there is no significant difference in terms of components pertaining to the promotion of professional ethics among faculty members at universities. Also, Kruskal Wallis Wallace test results have been reported for examining the age role (conversion to classified variable) in components professional ethics in the following table. 
Table 7. Kruskal Wallis test for investigating professional ethics difference in age groups

\begin{tabular}{lllll}
\hline Group variable & Dependent variable & Chi-two & Freedom degree & Sig. \\
\hline Age & Responsibility taking & $5 / 067$ & 3 & $0 / 167$ \\
& Justice & $3 / 265$ & 3 & $0 / 353$ \\
Candor & $2 / 93$ & 3 & $0 / 402$ \\
& Benefaction & $2 / 116$ & 3 & $0 / 549$ \\
& Organizational culture & $0 / 667$ & 3 & $0 / 881$ \\
& Organizational structure & $0 / 383$ & 3 & $0 / 944$ \\
& Management and organizational leadership & $0 / 921$ & 3 & $0 / 80$ \\
& Environmental factor & $2 / 293$ & 3 & $0 / 514$ \\
\hline
\end{tabular}

Kruskal Wallis test results indicate that there is no significant difference between various age levels of faculty members in components pertaining to the promotion of professional ethics.

Table 8. Kruskal Wallis test for investigating professional ethics difference in educational majors

\begin{tabular}{lllll}
\hline Group variable & Dependent variable & Chi-two & Freedom degree & Sig. \\
\hline Age & Responsibility taking & $2 / 42$ & 3 & $0 / 49$ \\
& Justice & $0 / 884$ & 3 & $0 / 829$ \\
& Candor & $1 / 508$ & 3 & $0 / 68$ \\
& Benefaction & $1 / 473$ & 3 & $0 / 688$ \\
& Organizational culture & $3 / 602$ & 3 & $0 / 308$ \\
& Organizational structure & $3 / 029$ & 3 & $0 / 387$ \\
& Management and organizational leadership & $3 / 259$ & 3 & $0 / 353$ \\
& Environmental factor & $5 / 496$ & 3 & $0 / 139$ \\
\hline
\end{tabular}

It is clear from the table above that there is no significant difference between educational majors of the faculty members with regards to the components pertaining to the professional ethics.

Third question: the question " which model is deemed appropriate for the promotion of professional ethics among the faculty members with regards to the dimension of education" can be restated as "Does the professional ethics, environmental areas, organizational structure organizational culture and management and leadership trajectory analysis model enjoy acceptable goodness of fit? Trajectory analysis results, by using empirical data indicate that variable professional ethics is directly or indirectly influenced by environmental area variables, organizational structure, organizational culture, management and leadership.

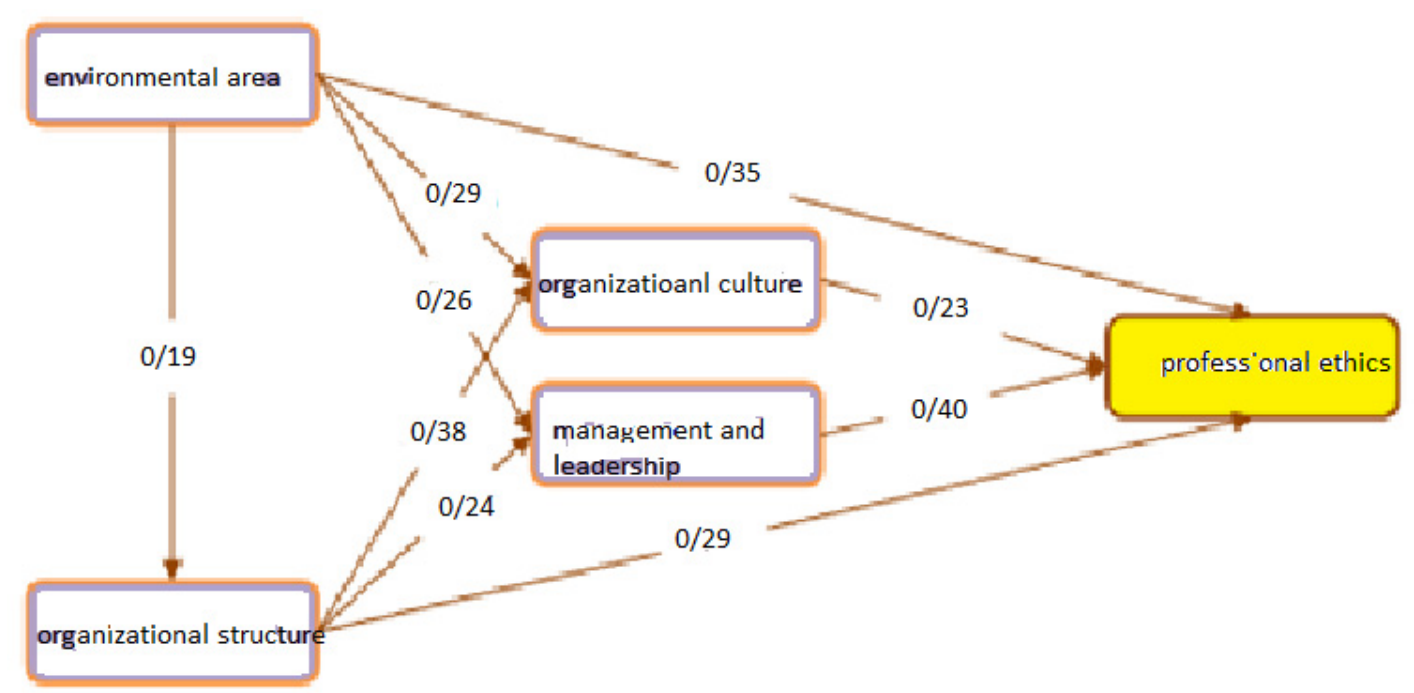

Figure 1. Standardized coefficients of professional ethics trajectory analysis 
Model goodness of fit indices have been provided in the following table.

Table 9. Model goodness of fit indices in the trajectory analysis

\begin{tabular}{llllllll}
\hline Index name & $\chi^{2}$ & RMSEA & IFI & NNFI & CFI & GFI & AGFI \\
\hline Goodness of fit sufficiency level & $\mathrm{P}=0 / 001$ & $0 / 077$ & $0 / 95$ & $0 / 94$ & $0 / 95$ & $0 / 91$ & $0 / 89$ \\
& $2846 / 9$ & & & & & & \\
\hline
\end{tabular}

The results of the above table suggest that all the indexes, except for the index AGFI have been reported at a high acceptance rate and the model has a goodness of fit with the data; this means that there is a linear relationship between the variables and current constructs. In other words, the presented conceptual model for anticipating professional ethics can very well predict professional ethics. In the following table, direct and indirect effects as well as the overall model variables have been provided accompanied by the statistic $\mathrm{t}$ :

Table 10. Coefficients and significance of direct and indirect effects and the overall predictive variables and criterion

\begin{tabular}{lllll}
\hline Predictive variable & Criterion variavke & Kind of effect & Standardized $\beta$ & T statistic \\
\hline Environmental areas & Organizational structure & Direct (total) & $0 / 19$ & $2 / 16$ \\
& Professional ethics & Direct & $0 / 35$ & $4 / 78$ \\
& & Indirect (via culture) & $0 / 10$ & $2 / 31$ \\
& & Indirect (via management ) & $0 / 14$ & $2 / 54$ \\
Organizational structure & Professional ethics & Total & $0 / 59$ & $7 / 70$ \\
& & Direct & $0 / 29$ & $4 / 12$ \\
& & Indirect (via culture) & $0 / 12$ & $2 / 40$ \\
Organizational culture & Professional ethics & Direct (total) & $0 / 14$ & $2 / 53$ \\
Management and leadership & Professional ethics & Direct (total) & $0 / 55$ & $7 / 24$ \\
\hline
\end{tabular}

$\mathrm{p}<0 / 05^{*}$

Given the above table results, it is evident all the direct and indirect and total trajectories from the variables are significant to each other. Given the above figure and model's goodness of fit induces, the model enjoys acceptance goodness of fit. This means that the intended variables possess the power to explain professional ethics. A detailed investigation of the trajectories reveals that then environmental area has a direct significant effect of $\beta=0 / 19$ on the organizational structure. The environmental area has a direct effect of $\beta=0 / 35$ and indirect effect (with intermediacy of culture) $\beta=0 / 1$ and indirect effect (with intermediacy of management) $\beta=0 / 14$ on professional ethics. Thus, the total effect (total of direct and indirect effects) of the environmental effects was $\beta=0 / 59$ on the professional ethics. The organizational structure had a direct effect of $\beta=0 / 29$ on professional ethics. Organizational structure also had an indirect effects (via culture) of $0 / 12$ and indirect effects (via management) of $\beta=014$ on professional ethics. Thus, the overall effects of organizational structure was estimated to be $\beta=0 / 55$ on the professional ethics. Organizational culture had a direct effects of $\beta=0 / 33$ and management and leadership had a direct effects of $\beta=0 / 4$ on the professional ethics. It is also clear that the highest direct effect relates to component management and leadership and via formulating an appropriate program in the connection of promotion of academic management quality, one can take a stride in line with the promotion of professional ethics. Later, a final model based on an investigation of research literature and texts and field stages results will be provided. 


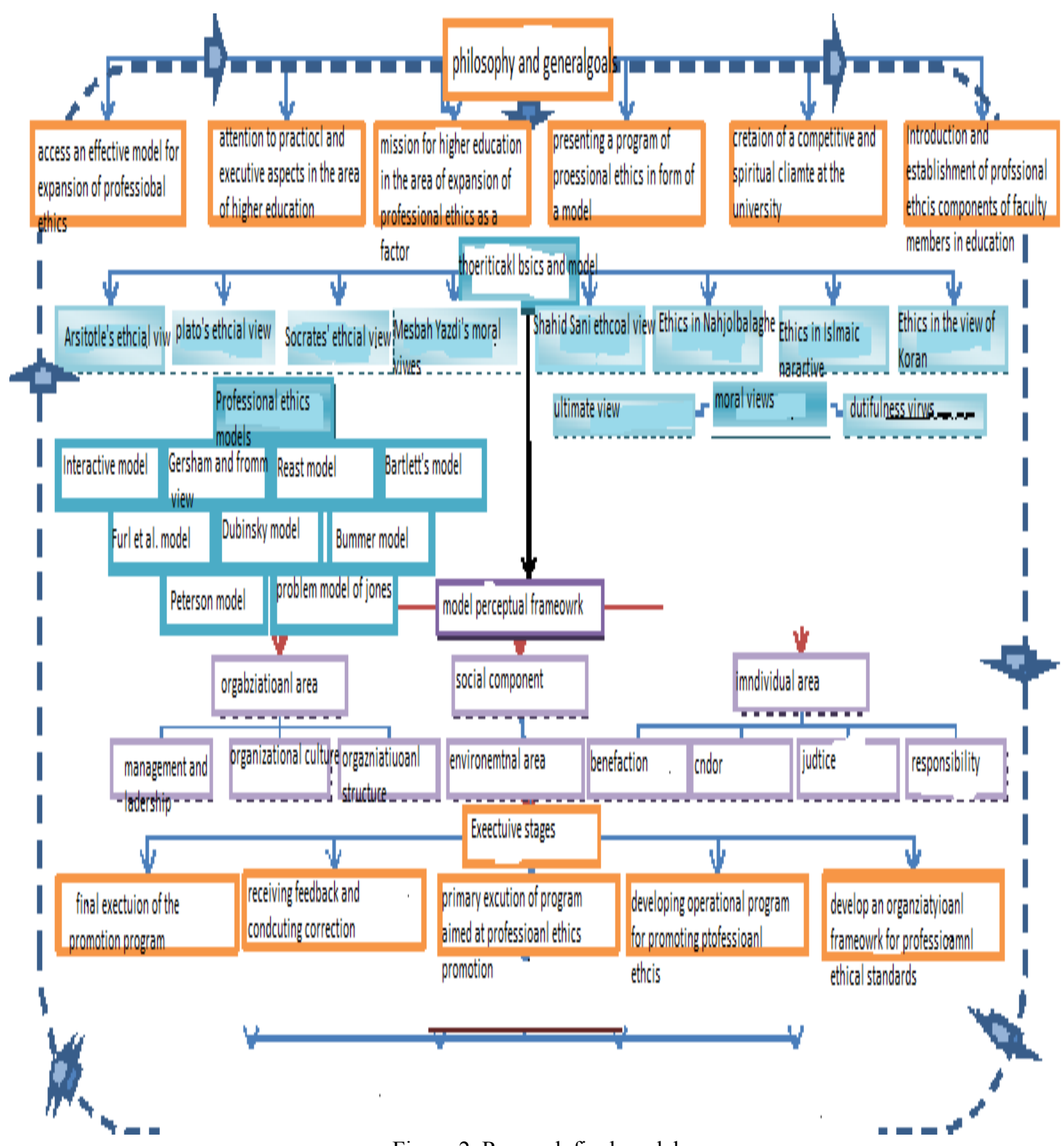

Figure 2. Research final model

Fourth question: In the end, the question to what degree this model fits is answered. In order to determine fitting degree of the professional ethics model, views of experts and scholars were used. For this, a questionnaire consisting of 5 elements, including philosophy and objective of the model, model's theoretical basics, perceptual framework, administrative stages and evaluation and feedback of the model were prepared and provide to 30 experts, scholars and proficient. In the questionnaire, while introducing each of the mention elements briefly, the respondents were asked to announce their own views on a seven degree scale. These five-fold elements are presented as follows:

\section{Philosophy and Objectives of the Model}

1) Introducing and establishing components for promoting professional ethics in the higher education;

2) Creating an ethical and spiritual competitive climate at universities;

3) Presenting a program for promoting professional ethics in form of a model; 
4) Creating a mission for the higher education in the area of development of professional ethics as a main factor of nurturing the human force at universities;

5) Attention to practical and administrative aspects of promoting professional ethics in the higher education;

6) Formulating a coherent model for promoting professional ethics in the higher education.

\section{Theoretical Basics}

The model theoretical basics of the model is derived from the Koran, Islamic narratives and views of the religious and philosophy figures as well as views of Islamic and Western thinkers. Zoroaster, one of the ancient Iranian thinkers, Socrates, Plato and Aristotle, among ancient Greek philosophers and Kant, as a great western thinker are among the examples who have expressed views in the field of significance of ethics; views of conscientiousness and ultimate in ethics and also theories of scholars like Bartel, Jones, Reast and Ferrel and Bummer and others in regard to ethical decision making models have addressed professional ethics from different perspectives. In this regard some have addressed professional ethics principles in the higher education, and from whom Evers (2000) has introduced five principles; these principles help professors and students to get engaged in researches and scientific crusade within the framework of professional ethics. Later, the significance of ethics from the standpoint of the Koran and Islamic Narratives is discussed and after that, the Evers' five principles are mentioned.

Ethics from the standpoint of the Koran: We taught Loghman Wisdom (faith and ethics) [and told him] to pray for God.

Significance of ethics in Islamic Narratives: The prophet states: I have just been sent for completing moral virtues.

Five principles by Evers:

a) Principle of respect for position and stature of humans' freedom: This principle refers to professors and students' respect for all humans disregard of color, race, ethnicity gender and religion. This principle helps them to act upon their own scientific duties disregard of any kind of political faction politicking;

b) Principle of conscientiousness and responsibility taking: professors and students have a feeling of responsibility against welfare and affairs relating to people in the society. While having concerns and taking responsibility, they need to make their efforts for removing their problems;

c) Principle of usefulness and non-infliction of harm: this principle is referred to strive by the higher education for communicating benefits to mankind. In addition to this, they attempt not to inflict nay harms to such people through their accomplishments and strive to minimize the level of harms on occasions when it is impossible to avoid it. It is regrettable that a lifetime attempt by Einstein was used for killing millions of humans in Japan;

d) Principle of non-discrimination: This principle refers to some mental and practical belief of professors and students based on which all people in then society have the right to use knowledge and their researches and hence, there must not be any difference among them;

e) Principle of attention to societal values system: Professors and researchers have always taken steps in the framework of values and social criteria and are obedient to them and their activities results must not hurt societal values (Evers, 2000);

Various professional ethics models have also been introduced, of which the following can be referred to:

* Bartels' model (1967): By considering some presumptions, he entered the following concepts into his own model:

1) Ethics is the criterion for determining the correctness of behavior;

2) Social interactions which is an area in which ethics judgment occurs;

3) Economic and non-economic structyure affects the individual behavior;

4) Expectations from an individual role includes ethical behavior of the individual;

5) Social laws are deemed as basics for ethical judgment more than technical requirements (Hunt \& Vithel, 1986).

\section{* Reast's model:}

This model explains how various cognitive structures and processes existing inside the ethical decision making 
process are combined for cresting the ethical behavior of an individual. The Reast's model involves four kinds of psychological kinds which occur for people so that they expose their ethical behaviors (Aylsworth, 2010). The four-fold model by Reast summaries the key points as follows:

a) Ethical sensitivity: Ethical sensitivity means interpreting peoples' action in relation with an overall assessment of a situation and existence of an ethical issue and that peoples' actions will affect others;

b) Ethical judgment: people need to make decisions regarding that which is correct. In other words, an individual must determine what act is ethical correct.

c) Ethical motivation: Definition and prioritization of ethical decisions. Based on this model, ethical values stand beyond individual values. Ethical values are commonly the first things which are intended in one decision. This stage includes development of ethical intentions and defining that which needs to be actually done and as a part of this stage, weak and strong points of each decision need to be determined by using the deciding person's feelings and perceptions.

d) Ethical action: over time, people need to have candor and self-recognition so that they always intended ethical values. The following figure illustrates the cognitive elements of ethical decision making based on their overall effects towards ethical decision making process (Ibid).

\section{* Ferrel and Gresham (1985):}

Ferrel and Gresham presented a proportionality framework for ethical decision making whose fundamental factors are:

- Individual cognitive structure: knowledge, values, beliefs, thinking manner and inclinations

- Special people in an organizational environment: managers, custodians and colleagues

- Situational conditions of an action (Crisp, 1995).

They admit that differences observed in ethical decision making are not random; rather the cause of differences observed are special factors which do exist in people, organizations and in interaction between people and organization. Individual factors are: knowledge, values, attitudes, and intention of people; organizational factors include an investigation of colleagues in the organization, leadership and management and monitoring (Ferrel and Gresham, 1985). They have also added factor "opportunity". They recommended peoples' decisions to be adopted in the scope of professional behavior regulation and policies and organizational procedures.

\section{* Trevion 's interactive model (1986):}

Trevino presented a testable relationship between various factors of decision making. Peoples' understanding (stage of cognitive ethical growth), individual modifiers (including individual power, background dependence and control center), and situational modifiers (including work features, organizational culture and current professional content) determine ethical and non-ethical behavior. Trevino stated that ethical decisions are affected by the interaction between people's cognitive variables and situation variables which include organizational culture, current professional content (enhancement and other pressures) and labor features. The assumption of the cognitive structure is that business decision makers get engaged in a rational and complicated analysis of the organizational setting. Ethical values, beliefs and the individual's thinking ways will specify the way the individual process a subject matter. However, processing is also affected by some organizational environmental factors (Cline, 2010).

\section{* Hunt and Vithel's general theory of ethics (1986):}

This theory explains two forms of an assessment process (which is derived from a traditional philosophical thinking) and is also applied by people in their own ethical judgment and act on that basis. In a result oriented process, an explanation of an activity is probably occurrence of results or outcomes of an action which affect the stakeholders. The result oriented approach is administered with the assumption of increasing acceptance. In the second process, Conscientious assessment pays attention to merit or virtuosity of the action which is assessed by invoking external ethical regulations or a group of values, nor $\mathrm{s}$ and rules. According to this theory, Conscientious and result oriented assessment of an ethical decision maker, in addition to affecting his ethical judgment will allow the person to go through ethical judgments or to deny then in the line of acquiring and avoiding some results. Thus, behavior can occur due to an estimation of some results. These two processes are like traditional processes which are raised by John Stuart Mill and Kant (Ronzoni, 2009).

\section{* Proportionality-problem model by Jones (1991):}

In 1991, Jones found out that none of the ethical decision making models included features of the problem itself. 
He claimed that each of the models sees the process of ethical decision making for all ethical discussions as the same and states that "when the issue is stealing some sources of an organization or providing some dangerous products to people, people won't behave the same". Therefore, Jones raises a proportionality model which includes a new structure and is called "ethical intensity" and this structure includes six features. In this model, ethical intensity has a direct effect on each of the four parts of the Rest's model (1986). Jones expanded the Rest' mode (1986) and entered the factor of probabilities into the ethical decision making model. Jones' model structure states that ethical issues vary from one situation to the other. For example, if the decision of an individual affects that of his close relatives, he will adopt a different decision.

\section{* Peterson's model (2001):}

This model is the only model that has specially designed and tested in the area of accounting. Peterson classifies factors affecting ethical decision making to three areas of which setting of industry, organizational $\mathrm{n}$ individual experience: setting of industry, organizational environment and individual experiences (Freeman, 2009).

\section{Perceptual Framework}

Perceptual framework includes three areas and seven components:

Individual area (components of taking responsibility, component of justice, component of candor and component of benefaction), organizational area (component of organizational culture, component of organizational structure component of management and component of organizational leadership at the university) and environmental component (social component).

\section{Model's Administrative Stages}

1. Formulating an organizational framework for professional ethics standards at the university;

2. Formulating an operational program for administration and promotion of professional ethics;

3. Preliminary administration of an operational program for promoting professional ethics;

4. Receiving of feedback and doing corrections;

5. Final administration of professional ethics promotion program

\section{Evaluation System and Feedback}

Evaluating the model is based on a stage evaluation and in a coherent form. In this model where the main parts involve an evaluation system are also placed in an overall evaluation process, such that all the parts are always placed under evaluation and feedback. Evaluation process includes:

1. Formulating an evaluation program;

2. Administering evaluation program;

3. Receiving feedbacks from universities and doing corrective measures;

4. Evaluating and renewed engineering based on developments and scientific and practical findings

Table 11. Model's validation table

\begin{tabular}{|c|c|c|c|c|c|c|c|c|c|c|c|c|c|c|}
\hline & \multicolumn{8}{|c|}{ Very appropriate } & \multicolumn{6}{|c|}{ Inappropriate } \\
\hline & 1 & & 2 & & 3 & & 4 & & 5 & & 6 & & 7 & \\
\hline & No. & Per. & No. & Per. & No. & Per. & No. & Per. & No. & Per. & No. & Per. & No. & Per. \\
\hline $\begin{array}{l}\text { Philosophy and } \\
\text { objective } 83 / 3 \%\end{array}$ & - & - & - & - & - & - & 5 & $16 / 6$ & 1 & $3 / 3$ & 21 & 70 & 3 & 10 \\
\hline $\begin{array}{l}\text { Theoretical basics } \\
93 / 26 \%\end{array}$ & - & - & - & - & - & - & 2 & $6 / 66$ & 2 & $6 / 66$ & 19 & $63 / 3$ & 7 & $23 / 3$ \\
\hline $\begin{array}{l}\text { Perceptual } \\
\text { framework } 90 \% \mathrm{k}\end{array}$ & - & - & - & - & - & - & 5 & 10 & 5 & $16 / .7$ & 12 & 40 & 10 & $33 / 3$ \\
\hline $\begin{array}{l}\text { Administrative } \\
\text { stages } 86 / 6 \%\end{array}$ & - & - & - & - & - & - & 7 & $13 / 3$ & 7 & $23 / 3$ & 14 & $46 / 7$ & 5 & $16 / 6$ \\
\hline $\begin{array}{l}\text { Renewed } \\
\text { engineering 90\% }\end{array}$ & - & - & - & - & - & - & 9 & 10 & 9 & 30 & 11 & $36 / 7$ & 7 & $23 / 3$ \\
\hline Total $86 / 6 \%$ & . & - & - & - & - & - & 9 & $13 / 3$ & 9 & 30 & 10 & $33 / 3$ & 7 & $23 / 3$ \\
\hline
\end{tabular}

Table results suggest that $83 / 3 \%$ of the group of experts have stated as appropriate philosophy and objectives of 
the model; $93 / 26 \%$ have determined theoretical basics as appropriate while $90 \%$ have determined the perceptual framework as appropriate; $86 / 6 \%$ have determined administrative stages as appropriate and $90 \%$ have determined evaluation system as good. Results also suggested that $86 / 6 \%$ found as acceptable the overall model.

\section{Conclusion}

The current research aimed to develop a model for promoting professional ethics of faculty members of the Islamic Azad University. The results of the qualitative part led to the identification of three areas and eight components where the results of the quantitative part reaffirmed the results of the qualitative part. Later, a detailed examination of the research questions and their comparison with other researches done in this regard will be addressed.

Data arising from the two research phases indicated that in the end, eight components are suitable for formulating a pattern for professional ethics of faculty members which are: individual area including: responsibility taking, justice, candor, benefaction; organizational area including: organizational culture, organizational structure management and leadership and environmental are which were examined in form of 81 items. Results were analyzed by using factorial analysis and indicated that the individual area consisting of four components explained $78 / 53 \%$ of its variance; organizational area consisted of 3 components which explained $68 / 96 \%$ of its variance and one factor was obtained within the environmental area that explained $86 / 82 \%$ of its variance. Examination of question two suggested that there was no significant difference between faculty members in terms of gender, age and educational major with regards to professional ethics and also analysis of third question suggest that the model developed for the professional ethics enjoyed acceptable goodness of fit. In the end, investigation of the model's validity of the fourth question suggested that from the view of faculty members, the mofel developed enjoys acceptable validity in five parts of philosophy and objectives, theoretical basics, perception framework, administrative stages and evaluation system. In a research with the title of Investigating professors' ethical perceptions, conducted at the University of New Zealand, Eweje and Brunton (2010) concluded that the from the view of academic professors the most important ethics components are: Possessing necessary scientific qualification for teaching, respect for students and realism and justice centeredness in evaluation. In this regard, they assigned the least score to avoiding discrimination among students. Oldenburg (2013) conducted a study with the aim of examining Students' attitudes to professors' ethical; issues. He found out that the most important ethical expectation of students from an ethics centered professor is respect for students and their ideas within various scientific areas and also application of proper ways of evaluation which are consistent with that which is taught. In a study with the heading of Examining educational ethical status of faculty members of state universities in the city of Tehran from the perspective of students in the M.A. course, Araste et al. (2010) did a research with a statistical population of all students studying in M.A. courses at the said universities with an inventory. The results which were obtained via using single sample $t$ tests as well as confirmatory factorial analysis suggested that academic professors attached significant value for the issue of ethics and its observance in teaching and paid attention to observing this issue as well as its principles and components in their own teaching processes. It is added that the components under measurement were: effectiveness of lesson's content, addressing sensitive subject matters, attention to the thinking growth of students, avoiding establishing a mutual relationship with students, respect for the university, respect for colleagues, keeping secrets and fair evaluation of students. Ayazi and colleagues (2010) did a research with the goal of Determining ethical characteristics of professors in line with effectiveness of education and found out that merit for teaching, maintaining position and stature of science and knowledge, giving science out for its followers, respect for students, attempts for making students creative with regards to higher traits and ethical values, equality between students, developing thinking among students, respect for rightfulness and fairness, intimacy with students, simplicity of expression, observing equality and spiritual directions are among the most significant traits of professors. In a study with the heading of Investigating and identifying ethical and professional indicators in teaching and education from the viewpoint of M.A. students which was conducted with a qualitative approach and by using a semi-structured interview tool, Motallebi Fard et al (2011) found out that except for the component of "respect for institution" and "keeping secret", other components obtained in the research by Murray et al. hold true at the university of Tarbyat Moalem in Tehran. In addition, their findings introduced component "resect for the classroom" also. The results of this research were consistent with those of Eweje and Brunton. The components extracted were inconsistent with those in studies by Oldenburg (2013), Ayazi et al. (2010) and Motallebi Fard et al. (2011). The results obtained affirm results of studies by Matthews and Murray (1991 and 1996).

Results obtained from this research and specification if relations between variables in this study suggest that professional ethics depends on many factors. One of the dimensions determined in this research are personal 
factors relating to the professors himself. A professor in two dimensions needs to oblige himself to observing ethical rules; firstly, due to a specula position and influence he exerts on behavior and thoughts of leaders and that' why he should know the most effective method in communicating ethical values. Secondly, because of a duty he is entrusted with for meeting students' expectations and he should follow maximum ethical rules while performing professional duties in his own educational responsibilities. Organizational factors are among other factors identified in this research. Higher education requires reengineering of processes in promoting hard professional ethics. Professional ethics, like any other ethics objectifies in a social arena. Ethical structures generate ethical subjective patterns and ethical subjective patterns generate ethical behaviors. The university as a system is made up of elements where each of the elements play their own functions and roles and there is interaction for establishing balance in this sister, and the result of synergy will lead to the survival of the system.

University is an organization consisting of heads and deans, staffs, students and educational departments, faculties and professors. Promoting professional ethics of faculty members at the university is affected by organizational factors (academic structure, academic culture, management and leadership of the university and students), and the faculty members, as number one players in promoting professional ethics are influenced by the directors and scenario writers. In other words, when professional ethics has roots in individual ethics, it is also affected by environmental and organizational factors and components; however, while emphasizing on the role of the environment, one can refer to this statement that " in the ethical world, an ethical man will grow" and in a non-ethical world, one cannot anticipate an ethical man. Organizational culture is among identified factors in this research. Organizational culture is a fundamental ground for the organizational development. Development and empowerment of human forces in each organization is the key for success of that organization and the faculty members are among the ones affected by the human force. Of components constituting prosperity of the faculty members is the professional and educational prosperity.

In the end, it has to be mentioned that given the fact that one of the fundamental responsibilities of the university is in the education dimension, one has to admit that professional ethics based education is one of the academic necessities and requirements which require attention by the officials, because teaching based on ethics will not only lead to increased efficacy of teaching, rather since it entails mental security in various levels for professors and students, the consequent results will be improvement in the qualitative and quantitative levels of the university.

\section{References}

Alizadeh, M., Abaszade, M., Shyshvany, H., \& Oral, M. (2010). Determining adherence to scientific ethics among faculty members (Case Study University of Tabriz). Fslnamh $\neg Y$ Politics, Science and Technology, 4, 68-57.

Araste, H. R., \& Jahed, A. (2011). Ethics in universities and centers of higher education: to improve treatment choices for each. Quarterly of Science, 1(2), 34-31.

Araste, H. R., Abraham's, G., \& Abdul, R. (2010). Check the status of the ethics faculty members in public universities in Tehran. Quarterly of culture strategy, 8-9.

Ayaz, Z., et al. (2010). Ethical standards in the effectiveness of the training. Seminar on Development of Medical Education of. March 11-12.

Aylsworth, K. (2010). Historical introduction to Philosophy and Deontological Ethics. Retrieved from http://en.wikiversity.org/wiki! Historical Introduction to Philosophy/Deontological Ethics

Azizi, \& Nemat, A. (2010). Professional Ethics in Higher Education (Reflections on strategies to improve ethical standards in academic training). Magazine culture strategy, 18-19, Ss.200-173.

Bergenhenegouwen, G. J. (2012). Professinal Code and Ethics for Training, Amsterdam. Journal of European Industerial Training, 20(4), 22-30.

Bourghani, F. S. (2011). Professional ethics. Correctional Magazine, 125-126, Ss.56- 48.

Bstanyan, J. (2011). Code of professional conduct. Journal of Accounting, 232, 56-50.

Cline, A. (2012). Deontology and Ethics: What is Deontology, Deontological Ethics? Retrieved from http://atheism.about.com/od/ ethicalsystems/a/Deontological.htm

Compbell, E. (2013). The Ethics of Teaching, As a Moral Profession. Curriculum Inquiry, 4(38), 357-385.

Creswell, J. W., Plano, C. V. L., Gutmann, M. L., \& Hanson, W. E. (2003). Advances in mixed methods research designs. In Tashakkori \& C. Teddlie (Eds.), Handbook of mixed methods in social and behavioral research 
(pp. 209-240).Thousand Oaks, CA: Sage.

Crisp, R. (1995). Deontological Ethics, in the Oxford Companion to Philosophy. Oxford University Press, p. 187.

Darling, H. L., \& Snyder, J. (2000). Authentic Assessment of Teaching in Context. Journal of Teaching and Teacher Education, 16, 523-545.

Evers, K. (2000). Formulationg International EthicsGuidelines for Science: Standing Committee onResponsibility and Ethics in Science. International Councilfor Science ICSU, 2000.

Eweje, G., \& Brunton, M. (2010). Ethical Perception of Teachers in Newzeland University. Journal of Business Ethics, 19(4), 95-111.

Fabrigar, I. R., Wegener, D. T., MacCallum, R. C., \& Strahan, E., J. (1999).Evaluating the use of exploratory factor analysis in psychological research. Psychological Method, 4(3), 272-299.

Farasatkhah, M. (2006). Scientific Ethics key to promoting higher education, scientific professional ethics in place mechanisms to guarantee the quality of higher education in Iran. Fslnamh $\neg Y$ Ethics in Science and Technology, 1, $26-13$.

Farmahinifarahani, M., \& Cup, B. L. (2012). Review of compliance with professional ethics of faculty members control components. Fslnamh $\neg Y$ Ethics in Science and Technology, 7(1), 10-1.

Ferrel, O. C., \& Gresham, L. G. (1985). A Contingency Framework for Understanding Ethical Decision Making in Marketing. Journal of Marketing, 49, 87-96.

Freeman, S. (2001). Deontology.in"Encyclopedia of Ethics", Second Edition, eds. Lawrence C. Becker and Charlotte B. Becker, Routledge Publishing, 1, 391.

Gharamaleki, F. A. (2006). Professional ethics. Tehran: Insane (2nd ed.).

Gharamaleki, F. A. (2009). Ethics in business organizations. Qom: publishing insane.

Gharamaleki, F. A. (2009). Introduction to professional ethics. Tehran: the pre-eminent.

Hejazi, R., \& Passenger, J. (2012). Sex with professional ethics in accounting relationship between university and society. Fslnamh $\neg Y$ Ethics in Science and Technology, 7(1), 58-50.

Hunt, S. D., \& Vitell, S. (1986). A General Theory of Marketing Ethics. Journal of Macramarketing, B, 5-16

Iman, P. M. (2012). Professional ethics in education. Iranian Journal of Medical Ethics and History, 5(6).

Matthews, J. R. (1991). The Teaching of Ethics and the Ethics of Teaching. Journal of Teaching of Psychology, $18(2), 80-85$.

Motalebifard, A., Nvehebrahim, A., \& Mohsenzadeh, F. (1390). Professional and ethical review and identify indicators from the point of view of postgraduate students in teaching and learning: a qualitative study. Quarterly of Ethics in Science and Technology.

Murray, H. et al. (1996). Ethical Principles in University Teaching. North York. Ontario: Society for Teaching and Learning in Higher Education (STLHE).

Murray, H., Gillese, E., Lennon, M., Mercer, P., \& Robinson, M. (1996). Ethical Principles in University Teaching. Society for Teaching and Learning in Higher Education. Eric, York University. Canada.

Nemati, M. A., \& Mohseni, H. S. (1983). Ethics higher education: Requirements and strategies. Journal of Strategic Research Centre, 63, 46-9.

Nemati, M. A., \& Mohseni, H. S. (2010). Ethics higher education:, requirements and strategies. Journal of Strategic Research Centre, 63, 46-9.

Oldenburg, Ch. (2013). Student Perceptions of Ethical Dilemmas Involving Professor. College Student Journal, 39(5), 129-141.

Reinhold, N. P. (2006). Moral man and Imoral society, chale's sono, New York.

Rest, J. R. (1986). Moral Development: Advances in Research and Therapy. New York: Praeger

Reybold, L. E., Halx, M. D., \& Jimenez, A. L. (2008). Professional integrity in higher education: Astudy of administrative ethics in student affairs. Journal of college studet development, 49(z), 110-124.

Ronzoni, M. (2009). Teleology, Deontology, and the Priority of Right: on some unappreciated distinctions, Ethical Theory and Moral Practice, Springer Netherlands. Retrieved from http://www.springerlink.com/ 
content! Dl 13224pgg318247/, pp. 2-6, 10-11, 19

Saki, R. (2011). Ethics training in preceding studies and its components. Quarterly of Ethics in Science and Technology, 2, 58-47.

Salehi, M. (2010). Professional ethics in management. Proceedings of billing, secretariat of conference, Islamic Azad University of Neka.

\section{Copyrights}

Copyright for this article is retained by the author(s), with first publication rights granted to the journal.

This is an open-access article distributed under the terms and conditions of the Creative Commons Attribution license (http://creativecommons.org/licenses/by/4.0/). 